\title{
The effect of functional movement screen and lower extremity training on hamstring/quadriceps ratio in football players
}

\author{
Akan Bayrakdar ${ }^{1 \mathrm{ABCDE}}$, Hilal Kılınç Boz ${ }^{2 \mathrm{ABCDE}}$ \\ ${ }^{1}$ Bingöl University, Turkey \\ ${ }^{2}$ Van Yüzüncü Yıl University, Turkey
}

Authors' Contribution: A - Study design; B - Data collection; C - Statistical analysis; D - Manuscript Preparation; E - Funds Collection.

\begin{abstract}
Purpose: $\quad$ The aim of this study is to determine the effect of functional movement screen and lower extremity training on hamstring/quadriceps $(\mathrm{H} / \mathrm{Q})$ ratio in football players.

Material: $\quad 11$ players from Sivas Belediyespor, affiliated to the Turkish Football Federation, participated in this study. The average age of the players involved in the study was $25.75 \pm 4.45$, height averages $178.49 \pm 8.72 \mathrm{~cm}$, and body weight averages $69.83 \pm 6.47 \mathrm{~kg}$. Players who participated in the study had previously suffered a knee area injury. In addition to team training for 8 weeks, extra exercises to strengthen their hamstring and quadriceps muscles were conducted 3 times a week. Isokinetic force tests and Functional Movement Screen (FMS) tests were conducted in the study. Data obtained were evaluated in SPSS package 24 program.

Results: $\quad$ There was a significant difference in the total score of FMS at the level of $p<0.05$. Deep squat $13.5 \%$, hurdle step $10.49 \%$, in line lunge $9 \%$, shoulder mobility $3.44 \%$, active straight $6.84 \%$, trunk stability push up $6.84 \%$, rotatuar stability $14.73 \%$ and FMS total score $17.24 \%$ showed improvement. There was a significant difference in the $\mathrm{H} / \mathrm{Q}$ ratio between both the right knee and left knee pre-test and post-test at $p<0.01$ level. The right knee developed at a rate of $600 \mathrm{H} / \mathrm{Q}$ at a rate of $17.24 \%$ and the left knee developed at a rate of $600 \mathrm{H} / \mathrm{Q}$.

Conclusions: As a result, 8 weeks of extra lower extremity exercises can be said to increase the H/Q ratio of football players. It is also seen that the FMS score has increased. Thus, it is thought that the risk of football players having a sports injury again is reduced.

Keywords: $\quad$ soccer players, lower extremity, exercise, Hamstring/quadriceps ratio, fonctional movement screen.
\end{abstract}

\section{Introduction}

Muscular strength is one of the most important components of sport, both for high performance and injury prevention. One of the most used methods to assess muscle strength balance between dominant/non-dominant and antagonist/agonist is isokinetic testing [1]. It has been suggested that bilateral strength differences and the ratio between maximal antagonist/agonist torques are related to several specific sport demands $[2,3]$.

Isokinetic assessment can be used to measure torque values at several joints in the body; the knee is perhaps the joint most commonly tested. This assessment typically involves comparing the involved joint with the uninvolved joint [4]. Isokinetic testing can be used to evaluate quadriceps and hamstrings muscle strength, providing a determination of the magnitude of torque generated, and subsequently, the hamstrings to quadriceps $(\mathrm{H}: \mathrm{Q})$ strength ratio $[5,6]$. A high incidence of knee injuries has been reported in sports activities such as soccer, handball, basketball, and other ball games [7, 8]. Thus, there is a strong need to assess potential physiological risk indicators to thereby prevent or reduce the occurrence of serious knee injury in athletes involved in high-risk sports $[9,10]$.

The contraction force of the quadriceps muscle during knee extension produces substantial anterior directed shear of the tibia relative to the femur at extended joint

(c) Akan Bayrakdar, Hilal Kılınç Boz, 2020 doi:10.15561/20755279.2020.0202 angles $[11,12]$. This shear can be counteracted not only by the anterior cruciate ligament (ACL) but also by hamstring coactivation [13]. Thus, low muscle strength of the hamstrings relative to quadriceps has been proposed to increase the risk of noncontact knee joint injuries [14, 15].

In the treatment of knee injuries, it is necessary to evaluate mobility and follow the development [16, 17]. Numerous methods for assessing movement proficiency exist; [18, 19] however, one popular test battery that has been examined in the literature is the functional movement screen $[20,21]$. The functional movement screen was originally designed to assess muscle flexibility, strength imbalances and general movement proficiency in a range of performance tests; identify functional deficits related to proprioception, mobilisation and stabilisation; and determine the existence of pain during any of the prescribed movement patterns [22]. Existing data suggest that the functional movement screen demonstrates moderate-toexcellent inter- and intra-rater agreement (kappa statistic $\geq 60 \%$ ) for most of the assessment protocols [23], and as a screening tool, is routinely used within both applied and clinical settings. Although the ability of the functional movement screen protocol to determine injury risk [16] and the effectiveness of training interventions [19] has been examined, the relationship between functional movement screen scores and physical performance remains limited [24]. But there are studies showing its full effect [25]. Few studies have formally investigated the use of the FMS ${ }^{\text {TM }}$ and its ability to predict injury in the 
athletic population [26, 27].

The aim of this study was to determine the effect of FMS and lower extremity exercises on H/Q ratio in footballers.

\section{Material and methods}

\section{Participants}

A total of 11 players played in Sivas Belediyespor, one of the 2. league teams of the Turkish Football Federation (TFF), participated in the study. The average age of the players involved in the study was $25.75 \pm 4.45$, height averages $178.49 \pm 8.72 \mathrm{~cm}$, and body weight averages $69.83 \pm 6.47 \mathrm{~kg}$.

\section{Research Design}

Players who participated in the study had previously suffered a knee area injury. In addition to Team Training (Table 1) for 8 weeks, extra exercises (Table 2 ) to strengthen their hamstring and quadriceps muscles were conducted 3 times a week. In this extra exercises, hamstring muscle strength development is higher than quadriceps muscle strength development, aiming to increase the H/Q Ratio. For this reason, movements for 2 hamstrings and 1 quadriceps muscle were applied. In addition, FMS measurements to determine the injury risks of footballers were made with the test method developed by physiotherapist Cook et al [18].

Warm-up procedure

Before the tests, the subjects undertook 5 minutes of low intensity aerobic run and 10 minutes of dynamic and static stretching of lower extremity muscles for general warm-up [28].

\section{Determination of isokinetic knee strength}

The lower extremity (knee) Isokinetic muscle strength of the football players involved in the study were measured by Isokinetic dynamometer. Players were given a total of 10 min warm-up before the test. Football players were administered concentric-concentric Isokinetic knee strength test with 10 repetitions of $60^{\circ} \mathrm{sec}^{-1}$ angular velocity on both legs 2 times, with the first measurement and the last measurement 8 weeks later.

Determination of Functional movement screen

According to the FMS method, athletes are given 0-3 points from each move. The athlete gets ' 3 ' points if he makes the move perfectly, ' 2 ' points if he makes the move with a few errors, ' 1 ' points if he makes it with many errors, and ' 0 ' points if he cannot make the move painfully. A maximum of ' 21 ' points can be scored at the end of the method. Athletes below 14 points may be at risk of injury.

Statistical Analysis.

The data obtained were evaluated in SPSS package 24 program. The Wilcoxon test from non-parametric tests was used for the detection of $\mathrm{H} / \mathrm{Q}$ ratios and FMs of football players. The level of significance in the study was considered to be $\mathrm{p}<0.05$.

\section{Results}

According to the table, there were no significant differences between deep squat, hurdle step, in line lunge, shoulder mobility, active straight, trunk stability push up and rotatuar stability in the FMS test battery. However, there was a significant difference in the total score of FMS at the level of $p<0.05$. Deep squat $13.5 \%$, hurdle step $10.49 \%$, in line lunge $9 \%$, shoulder mobility $3.44 \%$, active straight $6.84 \%$, trunk stability push up $6.84 \%$, rotatuar stability $14.73 \%$ and FMS total score $17.24 \%$ showed improvement. There was a significant difference in the $\mathrm{H} / \mathrm{Q}$ ratio between both the right knee and left knee pre-test and post-test at $\mathrm{p}<0.01$ level. The right knee developed at a rate of $600 \mathrm{H} / \mathrm{Q}$ at a rate of $17.24 \%$ and the

Table 1. Percentage distributions of football players based on the duration of team training for 8 weeks

\begin{tabular}{ll}
\hline Training Type & Percentage Distributions of Training \\
\hline Warming and regeneration & $23.56 \%$ \\
Aerobic and Anaerobic endurance & $27.06 \%$ \\
Speed and coordination & $9.55 \%$ \\
Strength & $15.92 \%$ \\
Technical, tactical and game forms & $23.88 \%$ \\
\hline
\end{tabular}

Table 2. Strength training program applied to football players

\begin{tabular}{|c|c|c|c|c|c|}
\hline Movement & Week/Day & $\begin{array}{l}\text { Number of } \\
\text { sets }\end{array}$ & $\begin{array}{l}\text { The number of } \\
\text { repetitions }\end{array}$ & Severity (\%of 1 RM) & Resting \\
\hline -Leg extansion & \multirow{4}{*}{3} & \multirow{4}{*}{3} & 8 & 80 & \multirow{4}{*}{30} \\
\hline -Leg curl & & & 6 & 85 & \\
\hline \multirow{2}{*}{$\begin{array}{l}\text {-Standing single leg } \\
\text { curl }\end{array}$} & & & 4 & 90 & \\
\hline & & & 2 & 95 & \\
\hline
\end{tabular}


Table 3. Comparison of pre-test and post-test measurements related to FMS and H/Q ratio of football group

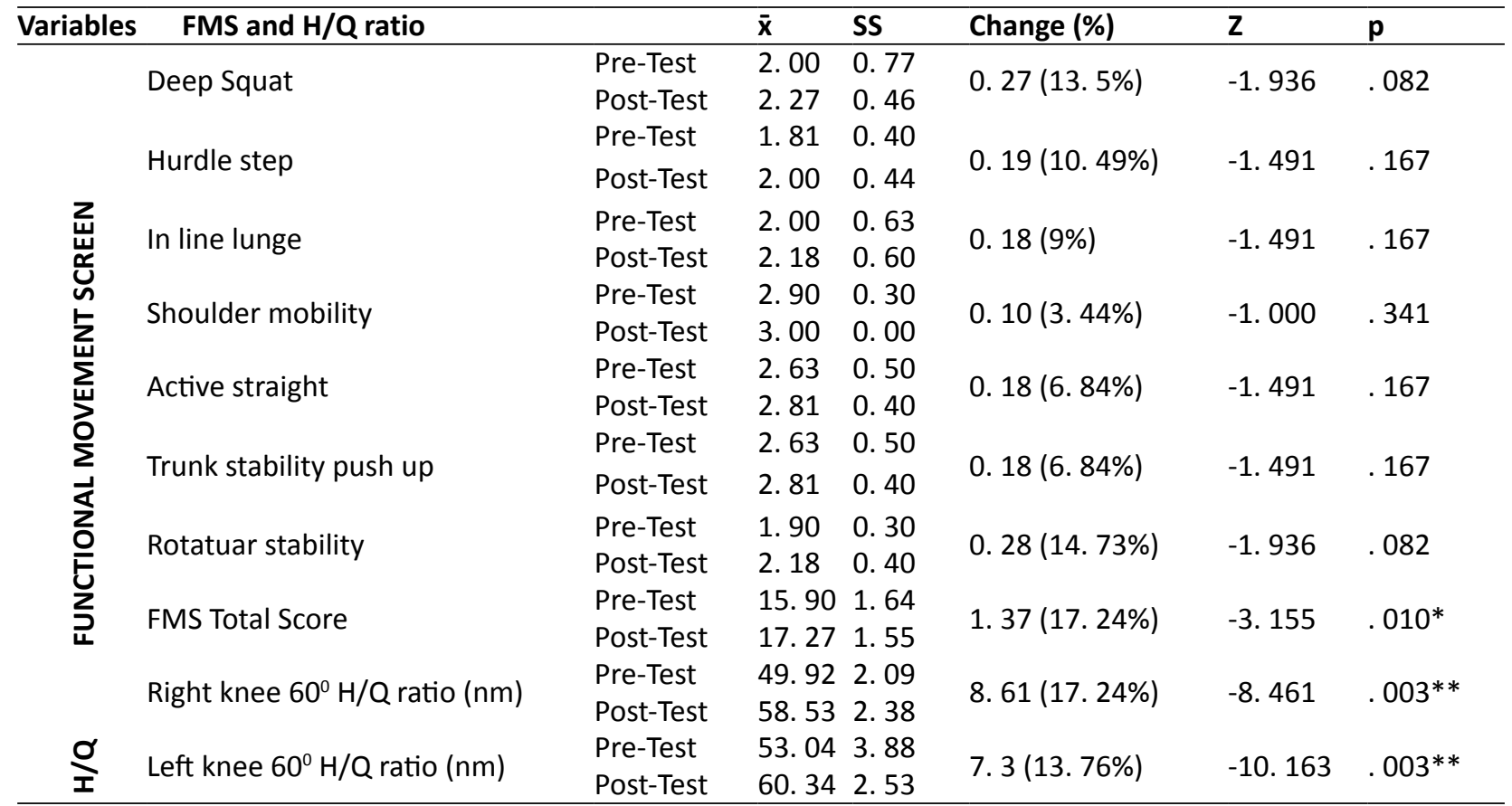

$P<0,05^{*} P<0.01^{* *}$

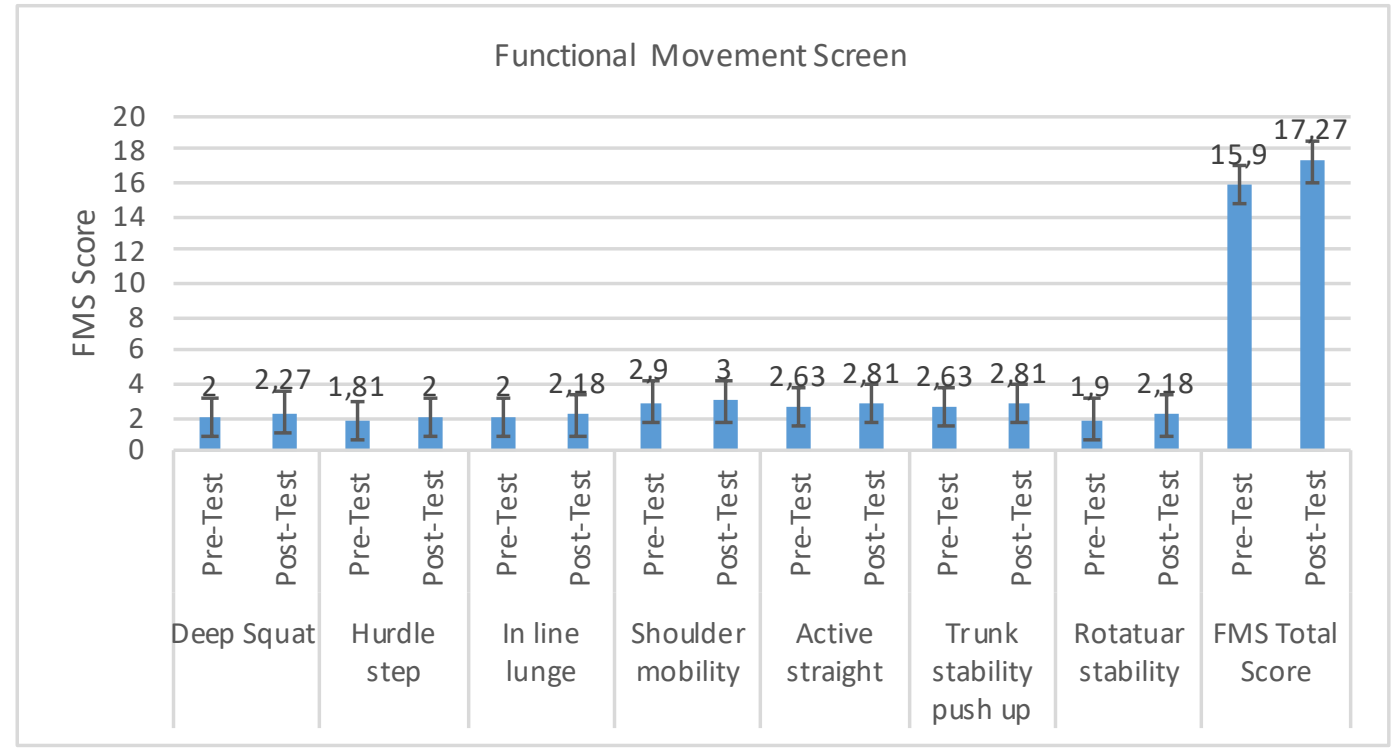

Figure 1. Football group pre-test and post-test FMS results

left knee developed at a rate of $600 \mathrm{H} / \mathrm{Q}$.

Development of lower extremity exercises except for normal training for 8 weeks are given in Figure 1 and Figure 2.

\section{Discussion}

Predict injuries all athletes, technical staff and by health professionals, although this is the most desirable destination; determining force ratios and muscle force ratios, the risk of injury, balance, coordination tests, environmental conditions, visual reaction time, and fatigue tests of multifactor assessment is required a contribution of many factors, such as proprioceptive [29].
Isokinetic testing of the $\mathrm{H} / \mathrm{Q}$ ratio provides a quantitative measurement of torque from agonist and antagonist muscle contraction surrounding the knee joint [30]. This ratio has also been examined as a possible screening tool for predisposition to injury [31]. When the knee is injured, the H/Q ratio is often used as a rehabilitative goal due to the importance of the flexor-extensor strength balance in overall knee stabilization [32]. Reduced function of the antagonist hamstrings due to activities that emphasize loads on the knee extensors may result in muscular imbalances between the hamstrings and quadriceps, thereby possibly predisposing athletes to injury. This predisposition may be due to the surrounding 


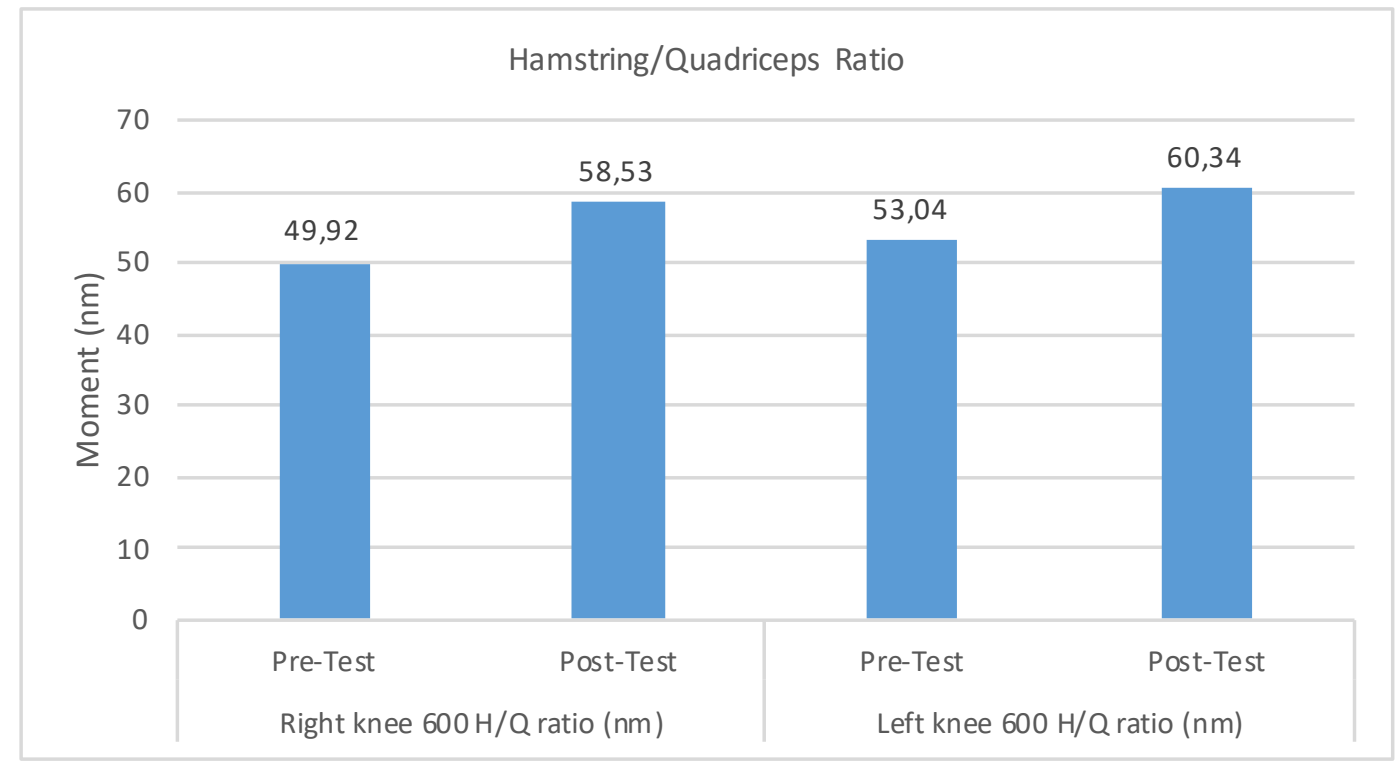

Figure 2. Football group pre-test and post-test $\mathrm{H} / \mathrm{Q}$ ratio results

ligamentous structures supporting most of the imposed load and decreased antagonist hamstrings coactivation during extension loads [33].

There was a significant difference in the H/Q ratio between both the right knee and left knee pre-test and the last test at $\mathrm{p}<0.01$ level. The right knee developed at a rate of $600 \mathrm{H} / \mathrm{Q}$ at a rate of $17.24 \%$ and the left knee developed at a rate of $600 \mathrm{H} / \mathrm{Q}$. Leg extension, leg curl and standing single Leg curl exercises applied to the lower extremity for 8 weeks were found to increase the H/Q Ratio positively significantly.

It is known in the literature that imbalance in the $\mathrm{H} / \mathrm{Q}$ Ratio is associated with weak hamstring muscle [34]. Balancing this ratio by reducing the force of the quadriceps is not possible since, exercises towards increasing hamstring strength should be performed. Given this situation, studies in which only hamstring-based exercises are performed to increase the H/Q strength ratio are available in the literature. For example, in this 2004 study, Mjolsnes divided 21 male players into Nordic hamstring crunchers and hamstring curl crunchers and had them performed for 10 weeks. The study concluded that the $\mathrm{H} / \mathrm{Q}$ ratio of Nordic hamstring crunchers increased, but there was no change in the H/Q ratio of hamstring leg curl crunchers [35]. Holcomb determined that 6 weeks of hamstring-based resistance exercises they performed on 12 international women football players significantly increased the H/Q ratio of the athletes [36].

There were no significant differences between deep squat, hurdle step, in line lunge, shoulder mobility, active straight, trunk stability push up and rotatuar stability in the FMS test battery. However, there was a significant difference in the total score of FMS at the level of $p<0.05$. Deep squat $13.5 \%$, hurdle step $10.49 \%$, in line lunge $9 \%$, shoulder mobility $3.44 \%$, active straight $6.84 \%$, trunk stability push up $6.84 \%$, rotatuar stability $14.73 \%$ and FMS total score $17.24 \%$ showed improvement.

In the literature, they reported the average FSM total score of 29 women football players as $15 \pm 2$ [37]. In another study, 15 women's soccer players reported an average FSM total score of 13.4, indicating eight injuries during the season [16]. They examined 27 women's soccer players from the direction of FSM and reported them as $16.5 \pm 2.1$ in the post-season [38]. As up-to-date information on injury mechanisms and ways to prevent is revealed, changing training schedules may have improved these scores, which determine the risk of injury. To support our findings, Sprague et al. and Chimera et al [36, 37]. The studies also reported scores were made before them by Chorba et al. the results in his study are higher [16].

As a result, 8 weeks of extra hamstring-weighted strength exercises applied to football players can be said to increase the H/Q Ratio. The positive effect of lower extremity exercise programs performed according to the FMS system on FMS score in football players and the low level of FMS score are thought to be directly related to injuries. While the tests suggested in this respect may give a hint of a general situation determination, the exact risk of injury should include a more comprehensive assessment.

Additionally, we believe that using the FSM test, which includes more comprehensive assessments for identifying injuries, will provide athletes with more detailed information. Future studies on this issue will guide the use of tests interchangeably or the deficiencies can be completed with other tests.

\section{Conclusion}

As a result, 8 weeks of extra hamstring-weighted strength exercises applied to football players can be said to increase the H/Q Ratio. The positive effect of lower extremity exercise programs performed according to the FMS system on FMS score in football players and the low level of FMS score are thought to be directly related to injuries. While the tests suggested in this respect may give a hint of a general situation determination, the exact risk of injury should include a more comprehensive 
assessment. Additionally, we believe that using the FSM test, which includes more comprehensive assessments for identifying injuries, will provide athletes with more detailed information. Future studies on this issue will guide the use of tests interchangeably or the deficiencies can be completed with other tests.

\section{Acknowledgements}

This study is the research article of Akan BAYRAKDAR and Hilal KILINÇ. No grants or financial aids were taken in this Project.

Financial support

There is no financial support.

\section{Conflict of interest}

The authors declare no conflict of interest.

\section{References}

1. Calmels P, Minaire P. A review of the role of the agonist/ antagonist muscle pairs ratio in rehabilitation. Disability and Rehabilitation, 1995; 17(6): 265-276. https://doi.org/10.3109/09638289509166646

2. Brown LE. Isokinetics in human performance. Human Kinetics; 2000.

3. Magalhaes J, Oliveir AJ, Ascensao A, Soares J. Concentric quadriceps and hamstrings isokinetic strength in volleyball and soccer players. Journal of Sports Medicine and Physical Fitness, 2004; 44:119-125.

4. Holmes JR, Alderink, GJ. Isokinetic strength characteristics of the quadriceps femoris and hamstring muscles in high school students. Physical therapy, 1984; 64(6), 914-918. https://doi.org/10.1093/ptj/64.6.914

5. Grace, TG, Sweetser ER, Nelson MA, Ydens LR, Skipper BJ. Isokinetic muscle imbalance and knee-joint injuries. A prospective blind study. The Journal of bone and joint surgery. American volume, 1984;66(5): 734- 740. https://doi.org/10.2106/00004623-198466050-00012

6. Rosene JM, Fogarty TD, Mahaffey, BL. Isokinetic hamstrings: quadriceps ratios in intercollegiate athletes. Journal of athletic training, 2001;36(4): 378.

7. Lind M, Menhert F, Pedersen AB. The first results from the Danish ACL reconstruction registry: epidemiologic and 2 year follow-up results from 5, 818 knee ligament reconstructions. Knee Surgery, Sports Traumatology, Arthroscopy, 2009;17(2): 117-124. https://doi.org/10.1007/s00167-008-0654-3

8. Myklebust G, Maehlum S, Engebretsen L, Strand T, Solheim E. Registration of cruciate ligament injuries in Norwegian top level team handball. A prospective study covering two seasons. Scandinavian journal of medicine \& science in sports, 1997;7(5):289-292. https://doi.org/10.1111/j.1600-0838.1997.tb00155.x

9. Östenberg A, Roos H. Injury risk factors in female European football. A prospective study of 123 players during one season. Scandinavian journal of medicine \& science in sports, 2000;10(5):279-285. https://doi.org/10.1034/j.1600-0838.2000.010005279.x

10.Zebis MK, Andersen LL, Ellingsgaard H, Aagaard P. Rapid hamstring/quadriceps force capacity in male vs. female elite soccer players. The Journal of Strength \& Conditioning Research, 2011;25(7):1989-1993. https://doi.org/10.1519/JSC.0b013e3181e501a6

11.Beynnon B, Howe JG, Pope MH, Johnson RJ, Fleming C. The measurement of anterior cruciate ligament strain in vivo. International orthopaedics, 1992;16(1):1-12. https://doi.org/10.1007/bf00182976

12.More RC, Karras BT, Neiman R, Fritschy D, Woo SL, Daniel DM. Hamstrings - an anterior cruciate ligament protagonist: an in vitro study. The American journal of sports Medicine, 1993; 21(2): 231-237. https://doi.org/10.1177/036354659302100212

13.Draganich LF, Vahey JW. An in vitro study of anterior cruciate ligament strain induced by quadriceps and hamstrings forces. Journal of Orthopaedic Research, 1990; 8(1): 57-63. https://doi.org/10.1002/jor.1100080107

14.Aagaard P, Simonsen EB, Beyer N, Larsson B, Magnusson $\mathrm{P}$, Kjaer M. Isokinetic muscle strength and capacity for muscular knee joint stabilization in elite sailors. International journal of sports medicine, 1997;18(7): 521-525. https://doi.org/10.1055/s-2007-972675

15. Hewett TE, Myer GD, Zazulak BT. Hamstrings to quadriceps peak torque ratios diverge between sexes with increasing isokinetic angular velocity. Journal of Science and Medicine in Sport, 2008;11(5): 452-459. https://doi.org/10.1016/j.jsams.2007.04.009

16.Chorba RS, Chorba DJ, Bouillon LE, Overmyer CA, Landis JA. Use of a functional movement screening tool to determine injury risk in female collegiate athletes. North American journal of sports physical therapy: NAJSPT, 2010;5(2): 47.

17.Clifton DR, Harrison BC, Hertel J, Hart JM. Relationship between functional assessments and exercise-related changes during static balance. The Journal of Strength \& Conditioning Research, 2013;27(4):966-972. https://doi.org/10.5923/j.sports.20160601.03

18.Cook G, Burton L, Hoogenboom B. Pre-participation screening: the use of fundamental movements as an assessment of function-part 1. North American journal of sports physical therapy: NAJSPT, 2006; 1(2): 62-72.

19. Frost D, Andersen J, Lam T, Finlay T, Darby K, McGill SM. The relationship between general measures of fitness, passive range of motion and whole-body movement quality. Ergonomics, 2013;56: 637-649. https://doi.org/10.1080/00140139.2011.620177

20.Okada T, Huxel KC, Nesser TW. Relationship between core stability, functional movement, and performance. The Journal of Strength \& Conditioning Research, 2011;25(1): 252-261. https://doi.org/10.1519/JSC.0b013e3181b22b3e

21.Parchmann CJ, McBride JM. Relationship between functional movement screen and athletic performance. The Journal of Strength \& Conditioning Research, 2011; 25(12):3378-3384. https://doi.org/10.1519/JSC.0b013e318238e916

22.Cook G, Burton L, Hoogenboom B. Pre-participation screening: the use of fundamental movements as an assessment of function-part 2. North American journal of sports physical therapy: NAJSPT, 2006;1(3); 132-139.

23.Teyhen DS, Shaffer SW, Lorenson CL, Halfpap J P , Donofry DF , Walker MJ, Childs JD. The functional movement screen: a reliability study. Journal of orthopaedic \& sports physical therapy, 2012;42(6): 530-540. https://doi.org/10.5114/biolsport.2018.77825

24.Lloyd RS, Oliver JL, Radnor JM, Rhodes BC, Faigenbaum AD, Myer GD. Relationships between functional movement screen scores, maturation and physical performance in young 
soccer players. Journal of sports sciences, 2015;33(1): 11-19. https://doi.org/10.1080/02640414.2014.918642

25.Peate WF, Bates G, Lunda K, Francis S, Bellamy, K. Core strength: A new model for injury prediction and prevention. JournalofOccupationalMedicineandToxicology,2007;2(1):3. https://doi.org/10.1186/1745-6673-2-3

26.Burton SL. Performance and injury predictability during firefighter candidate training [Doctoral dissertation]. Virginia Tech; 2006.

27.Kiesel K, Plisky PJ, Voight ML. Can serious injury in professional football be predicted by a preseason functional movement screen. North American journal of sports physical therapy: NAJSPT, 2007;2(3):147.

28. Yilmaz A, Kabadayi M, Mayda M, Birinci M, Özdal M. The effects of isokinetic knee strength on the promptness of soccer players. European Journal of Physical Education and Sport Science, 2017; 3(11): 114-123. https://doi.org/10.5281/zenodo.1011100

29.Koçak UZ, Ünver B. Kadın Futbolcularda Yaralanma Riski Belirleyicileri Olarak Fonksiyonel Hareket Analizi ve Y Denge Testi Arasındaki İlişkinin İncelenmesi. Spor Hekimliği Dergisi, 2019;54(1): 001-008. https://doi.org/10.5152/tjsm.2019.110

30.Snow CJ, Cooper J, Quanbury AO, Anderson J E. Antagonist cocontraction of knee extensors during constant velocity muscle shortening and lengthening. Journal of Electromyography and Kinesiology, 1995; 5(3): 185-192. https://doi.org/10.1016/1050-6411(95)00007-m

31.Bennell K, Wajswelner H, Lew P, Schall-Riaucour A, Leslie $\mathrm{S}$, Plant D, Cirone J. Isokinetic strength testing does not predict hamstring injury in Australian Rules footballers. British journal of sports medicine, 1998;32(4): 309-314. https://doi.org/10.1136/bjsm.32.4.309
32.Holm I, Ludvigsen P, Steen H. Isokinetic hamstrings/ quadriceps ratios: normal values and reproducibility in sport students.IsokineticsandExerciseScience, 1994;4(4): 141-145. https://doi.org/10.3233/IES-1994-4403

33.Baratta R, Solomonow M, Zhou BH, Letson D, Chuinard RD'ambrosia R. Muscular coactivation: the role of the antagonist musculature in maintaining knee stability. The American journal of sports medicine, 1988;16(2): 113-122. https://doi.org/10.1177/036354658801600205

34. Yamamoto T. Relationship between hamstring strains and leg muscle strength. A follow-up study of collegiate track and field athletes. The Journal of sports medicine and physical fitness, 1993; 33(2): 194-199.

35.Mjølsnes R, Arnason A, Østhagen T, Raastad T, Bahr R. A 10-week randomized trial comparing eccentric vs. concentric hamstring strength training in welltrained soccer players. Scandinavian journal of medicine \& science in sports, 2004;14(5):311-317. https://doi.org/10.1046/j.1600-0838.2003.367.x

36.Holcomb WR, Rubley MD, Lee HJ, Guadagnoli MA. Effect of hamstring-emphasized resistance training on hamstring: quadriceps strength ratios. Journal of Strength and Conditioning Research, 2007;21(1): 41. https://doi.org/10.1519/R-18795.1

37.Chimera NJ, Smith CA, Warren M. Injury history, sex, and performance on the functional movement screen and Y balance test. Journal of athletic training, 2015; 50(5): 475-485. https://doi.org/10.4085/1062-6050-49.6.02

38.Sprague PA, Mokha GM, Gatens DR. Changes in functional movement screen scores over a season in collegiate soccer and volleyball athletes. The Journal of Strength \& Conditioning Research, 2014;28(11):3155-3163. https://doi.org/10.1519/JSC.0000000000000506

\section{Information about the authors:}

Akan Bayrakdar; (Corresponding author); http://orcid.org/0000-0002-3217-0253; akanbayrakdar@gmail.com; School of Physical Education and Sport, Bingöl University; School of physical education and sport, Bingöl University, 12000, Bingöl, Turkey:

Hilal Kılınç Boz; http://orcid.org/0000-0002-6499-0555; hilalkilinc@msn.com; School of Physical Education and Sport, Van Yüzüncü Yıl University; Van Yüzüncü Yıl University Zeve Campus, 65080 Tuşba /VAN, Turkey.

Cite this article as:

Akan Bayrakdar, Hilal Kılınç Boz. The effect of functional movement screen and lower extremity training on hamstring/ quadriceps ratio in football players. Physical education of students, 2020;24(2):80-85. https://doi.org/10.15561/20755279.2020.0202

This is an Open Access article distributed under the terms of the Creative Commons Attribution License, which permits unrestricted use, distribution, and reproduction in any medium, provided the original work is properly cited http://creativecommons.org/licenses/by/4.0/deed.en

Received: 16.02 .2020

Accepted: 18.03.2020; Published: 30.04.2020 